\title{
The representation of gender and inflectional class in Italian: A reply to Kučerová 2018*
}

\author{
Pietro Baggio Yasutada Sudo
}

\begin{abstract}
In a recent article, Kučerová 2018 (henceforth K18) puts forward a novel theory of the morphology and interpretation of nominal gender in Italian. This paper takes issue with this theory from both empirical and theoretical standpoints. We first show that several generalisations presented as empirical support for it are in fact incorrect. We then point out a series of fundamental challenges for the theory. First, the proposed three-way classification of nouns misrepresents the full range of facts, because it does not take into account plural morphology or the interdependencies of CLASS and GENDER features. Second, the account of gender mismatch in terms of "semiconservativity" fails to capture the Italian data, once the full paradigm is considered. Finally, K18's use of Phase Theory to model contextual valuation of gender faces an insurmountable lookahead problem.
\end{abstract}

Keywords: gender, inflectional class, Italian, Maximize Presupposition

\section{Introduction}

In a recent article in the present journal, Kučerová 2018 (henceforth K18) puts forward a theory of the morphology and interpretation of nominal gender in (Standard) Italian, which builds on a number of novel theoretical ideas. In this paper, we take issue with this theory from both empirical and theoretical standpoints. First, $\$ 2$ shows that certain generalisations presented in K18 as crucial empirical support are in fact incorrect. $\$ 3$ then presents a series of further empirical facts about the interaction of gender, number, and class that pose foundational challenges to K18's theory. In particular, the proposed three-way classification of nouns misrepresents the full range of facts, because essential data, invovling plural morphology and the interdependencies of CLASS and GENDER features. $\$ 4$ concentrates on two issues arising from the use of Phase Theory in K18. $\S 4.1$ argues that, once the full paradigm is brought into view, K18's account of gender mismatch cannot capture the Italian data, and $\$ 4.2$ shows that Phase Theory is in fact fundamentally incompatible with another crucial component of K18's model, namely, contextual valuation of gender.

\footnotetext{
*We would like to thank the two anonymous reviewers for Linguistic Inquiry for constructive and helpful feedback. All remaining errors are our own.
} 
Let us begin with a brief review of the theory. K18 identifies three classes of nouns in Italian, each listed differently in the lexicon, as shown below. ${ }^{1}$

1. Conservative nouns (e.g. mano $_{F}$ 'hand', libro $_{M}$ 'book') are invariant with respect to gender (as evidenced by agreement) and inflectional class. They are listed with an $n$ specifying class and gender features, e.g. $\left[{ }_{n \mathrm{P}} n_{\text {[CL:o/i,GEN: F] }} \sqrt{\mathrm{MAN}-}\right]$

2. Semiconservative nouns (e.g. testimone ${ }_{M / F}$ 'witness' ${ }^{2}$ ) are invariant with respect to inflectional class but can agree both in feminine and masculine gender. They are listed with an $n$ specifying class but not gender, e.g. $\left[_{n \mathrm{P}} n_{\text {[CL:e/i] }} \sqrt{\text { TESTIMON-] }}\right.$

3. Liberal nouns (e.g. figlio $_{M}-$ figlia $_{F}$ 'child') can bear either gender value, and the choice of gender determines the inflectional ending: $o / i$ for masculine, $a / e$ for feminine. They are listed as bare roots, e.g. $\sqrt{\text { FIGLI- }}$

The gender of semiconservative and liberal nouns is not determined from the lexicon, but can be valued in two alternative ways: if the noun has an animate referent, it must be 'valued from the context' in a way that reflects the noun's semantics. §4.2 will discuss this idea in detail, and argue that it does not ultimately hold together. On the other hand, if the referent is inanimate, contextual valuation is impossible and default masculine is assigned as a last resort. K18 furthermore proposes that the distinction between lexically vs. contextually valued gender maps onto the divide between "grammatical" and "natural" gender: gender features valued in the lexicon are never semantically interpreted and, conversely, those valued contextually always are.

Lastly, inflectional class can be determined in two ways: in (semi)conservative nouns it comes from the valued [CL] feature on $n$, while in liberal nouns from last resort PF rules that realise [GEN:M] as default $-o / i$ and [GEN:F] as default $-a / e$.

Before proceeding further, note that this three-way typology already raises some unanswered questions. First, there are some inanimate nouns that can bear either gender (see esp. Acquaviva 2008). In some cases, there are systematic differences in meaning correlating with differences in gender, as with tree-fruit noun pairs (e.g. melo $_{M}-$ mela $_{F}$ 'apple (tree)-apple (fruit)'). In others, differences in meaning are idiosyncratic and markedly subtle (e.g. buco $_{M}-$ buca $_{F}$ '(bi-dimensional) hole-(three-dimensional) hole', from Acquaviva 2008: 130), so much so that they can often be reduced to frequency, con-

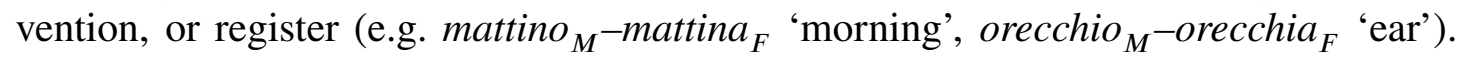
Details aside, it is unclear how these nouns fit within K18's system. The observed alternations suggest that these roots are stored without a gender specification, but in that case the system always predicts default masculine, because contextual gender valuation is not available for inanimates. Perhaps the model could be augmented with additional feature-valuation mechanisms, or the lexicon expanded to include sets of phonologically

\footnotetext{
${ }^{1}$ Abbreviations are as follows. CL: inflectional class, F: feminine, GEN: gender, M: masculine, NUM: number, PL: plural, s: singular. K18 uses numerals (1-3) for noun classes. We use instead the notation $x / y$, where $x$ is the singular suffix and $y$ its plural counterpart (cf. $\S 3$ for explicit motivations).

${ }^{2} \mathrm{~K} 18$ uses the nouns chirurgo 'surgeon' and soprano 'soprano' as examples of semiconservativity. However, this raises serious issues, which will be discussed in $\$ 4.1$. Relatedly, K18 reports inter-speaker variation between conservativity and semiconservativity for soprano-type nouns. On the other hand, there is no inter-speaker variation for nouns like testimone 'witness'.
} 
and semantically near-identical nouns listed as separate entries. This remains an open question for K18.

On a similar note, an anonymous reviewer points out a handful of nouns whose inflectional endings alternate freely between two classes (pace Kučerová 2018: 818,

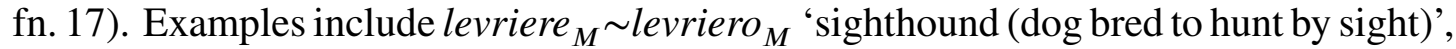
stratega $_{M} \sim$ stratego $_{M}$ 'strategist', and scoliasta $_{M} \sim$ scoliaste $_{M}$ 'scholiast (author of commentary on ancient manuscripts)' (differences are stylistic). If these nouns are listed with no class specification, nothing in K18's model can predict the variation in inflectional ending: the default PF realisation $o / i$ would be expected in all cases. In fact, K18's system predicts no detectable difference between conservative nouns with [CL:o/ $i$, GEN:M], hypothetical semiconservative nouns with [GEN:M], inanimate semiconservative nouns with [CL:o/i], and inanimate liberal nouns. We leave these as open questions, and proceed with our more directed criticism.

\section{Purported Empirical Support}

We begin by reviewing some of the data presented in K18 as support for the theory, and showing that many of the purported generalisations are empirically problematic. With this out of the way, we will proceed to raise more substantial analytical and theoretical issues, and discuss them at length in $\S 3$ and $\S 4$. Readers mainly interested in the latter may therefore feel free to skip this section.

\subsection{Noun-verb pairs}

It is remarked in K18 that only liberal nouns can have verbal counterparts with the bare root followed directly by the inflectional suffix -are in place of the nominal theme vowel. This is argued to be a good prediction, because only liberal nouns are listed as categoryneutral roots in the lexicon so only they can combine directly with verbal inflection in the absence of denominal derivational morphology. However, noun-verb pairs that directly contradict the generalisation can be found in profusion, as demonstrated in Table 1. These examples in Table 1 are doubly problematic. First, although not necessarily incompatible with the theory advanced in K18, noun-verb pairs turn out to provide no support for it and question its empirical rationale. Second, given K18's own assumptions, the data in Table 1 suggests that the roots of liberal nouns are no more categoryneutral than those of (semi)conservative nouns, casting doubt on the suggestion that the latter, but not the former, should be listed in the lexicon as nouns, which is one of the fundamental tenets of K18's theory.

\subsection{Loanwords}

It is assumed throughout $\mathrm{K} 18$ that Italian inflectional class must be exponed by a vowel suffix, and that no noun can be lexically specified for gender but not for class. It then follows that any loanword ending in a consonant, lacking a class marker, cannot be associated with any inflectional class and cannot encode gender in the lexicon. As a consequence, the only way for such a loanword to be associated with gender is via contextual 


\begin{tabular}{|c|c|c|c|}
\hline \multicolumn{2}{|c|}{ GEN:M - CL:o/ $i$} & \multicolumn{2}{|c|}{ GEN:F - CL: $a / e$} \\
\hline $\begin{array}{l}\text { NOUN } \\
\text { cemento 'cement' } \\
\text { martello 'hammer' } \\
\text { alito 'breath' } \\
\text { pavimento 'floor' } \\
\text { ghiaccio 'ice' } \\
\text { suono 'sound' } \\
\text { calcio 'kick' }\end{array}$ & $\begin{array}{l}\text { VERB } \\
\text { cementare 'cement' } \\
\text { martellare 'hammer' } \\
\text { alitare 'exhale' } \\
\text { pavimentare 'pave' } \\
\text { ghiacciare 'freeze' } \\
\text { suonare 'play' } \\
\text { calciare 'kick' }\end{array}$ & $\begin{array}{l}\text { NOUN } \\
\text { scala 'ladder' } \\
\text { pianta 'plant' } \\
\text { spiaggia 'beach' } \\
\text { macchina 'machine' } \\
\text { multa 'fine (fee)' } \\
\text { cena 'dinner' } \\
\text { ruota 'wheel' }\end{array}$ & $\begin{array}{l}\text { VERB } \\
\text { scalare 'climb' } \\
\text { piantare 'plant' } \\
\text { spiaggiare 'beach' } \\
\text { macchinare 'plot' } \\
\text { multare 'fine' } \\
\text { cenare 'have dinner' } \\
\text { ruotare 'revolve' }\end{array}$ \\
\hline \multicolumn{2}{|c|}{ GEN:M - CL:e/i } & \multicolumn{2}{|c|}{ GEN:F - CL:e/i } \\
\hline $\begin{array}{l}\text { NOUN } \\
\text { sale 'salt' } \\
\text { pepe 'pepper' } \\
\text { colore 'colour' } \\
\text { odore 'smell' } \\
\text { genere 'gender' } \\
\text { concime 'manure' } \\
\text { regime 'regime' }\end{array}$ & $\begin{array}{l}\text { VERB } \\
\text { salare 'salt' } \\
\text { pepare 'pepper' } \\
\text { colorare 'colour' } \\
\text { odorare 'smell' } \\
\text { generare 'generate' } \\
\text { concimare 'fertilize' } \\
\text { regimare 'regulate' }\end{array}$ & $\begin{array}{l}\text { NOUN } \\
\text { stagione 'season' } \\
\text { occasione 'occasion' } \\
\text { canzone 'song' } \\
\text { visione 'vision' } \\
\text { chiave 'key' } \\
\text { stazione 'station' } \\
\text { vernice 'paint' }\end{array}$ & $\begin{array}{l}\text { VERB } \\
\text { stagionare 'season' } \\
\text { occasionare 'cause' } \\
\text { canzonare 'tease' } \\
\text { visionare 'view' } \\
\text { chiavare 'fuck' } \\
\text { stazionare 'stay' } \\
\text { verniciare 'varnish' }\end{array}$ \\
\hline \multicolumn{2}{|c|}{ GEN:M - CL: $a / i$} & & \\
\hline $\begin{array}{l}\text { NOUN } \\
\text { sistema 'system' } \\
\text { diploma 'diploma' } \\
\text { poeta 'poet' } \\
\text { pilota 'pilot' } \\
\text { programma 'schedule' }\end{array}$ & $\begin{array}{l}\text { VERB } \\
\text { sistemare 'arrange' } \\
\text { diplomare 'graduate' } \\
\text { poetare 'make poetry' } \\
\text { pilotare 'pilot' } \\
\text { programmare 'plan' }\end{array}$ & & \\
\hline
\end{tabular}

Table 1: Examples of noun-verb doublets with conservative nouns.

gender valuation or default masculine as a last resort. Since contextual valuation requires an animate referent, all inanimate loan nouns ending in consonant are predicted to be masculine. This is presented in K18 as a correct prediction.

While a large number of loanwords are indeed masculine, feminine inanimate nouns are also amply attested amongst borrowings, as exemplified below. ${ }^{3}$

Feminine inanimate loans from English

audience, cache, chat ${ }^{4}$, cheesecake, clearance, compilation, cover, escalation,

\footnotetext{
${ }^{3}$ Ferrari (2005) observes that in her database of 4, 309 nouns there are 266 loanwords, of which 25 (or 9.3\%) are feminine. This is not a negligible proportion and it cannot be ignored: K18's model fails to predict the existence of roughly 1 out of 10 loan nouns (see also Ferrari-Bridgers 2008).

${ }^{4}$ Incidentally, the noun chat is mentioned on p. 823 of K18 as an example of a masculine loanword from English. As a matter of fact, chat is invariably feminine in Italian. We suspect the inaccuracy may be due to a confusion with the masculine noun khat 'khat (shrub, stimulant)', a loanword from Arabic that may occasionally be spelled also as qat/chat.
} 
gang, intelligence, internet, leadership, location, (e)mail, nomination, overdose $e^{5}$, password, performance, playlist, reception, sitcom, standing ovation, taskforce, webcam, ...

(2) Feminine inanimate loans from French

baguette, brioche, chance, coque (in uovo alla coque 'soft-boiled egg'), crêpe, cyclette ('exercise bike'), gaffe, limousine, manicure, mascotte, moquette, mousse, omelette, pedicure, roulotte ('caravan'), routine, silhouette, toilette, ...

Given that the theory in K18 predicts the complete nonexistence of these nouns, it cannot be correct in its current form. To accommodate the data, it could be expanded to include a further inflectioanl class $\varnothing / \varnothing$, realised uniformly by a null suffix ${ }^{6}$. The loanwords in (1)-(2) would then be conservative nouns with GEN:F and CL: $\varnothing / \varnothing$. Be that as it may, we see once more that evidence presented in favour of the theory fails to withstand further empirical scrutiny. The interested reader is referred to Thornton (2009) for a detailed discussion of gender patterns in loanwords and neologisms.

\subsection{V-N compounds}

Before leaving this section, a further-albeit minor-empirical objection is worth noting. In Kučerová 2019, a closely related paper that presents and expands on the first section of K18, it is argued that the same theory correctly predicts that inanimate V-N compounds are all masculine, even when they contain a feminine noun: e.g. [asciugamano $\left._{F}\right]_{M}$ (dry-hand.FS) 'hand towel' and [ bacia-mano $\left._{F}\right]_{M}$ (kiss-hand.FS) 'hand kiss'. $\mathrm{V}-\mathrm{N}$ compounds are assumed to have the structure in (3), where the VP layer creates a locality boundary preventing the higher functional nodes (e.g. D and $n$ ) from accessing the gender feature of the noun. If the referent is inanimate, contextual gender valuation is impossible and the compound is predicted to bear default masculine.

$$
\left.\left.\left[\begin{array}{lllllllllll}
\mathrm{DP} & \mathrm{D} & { }_{n \mathrm{P}} & n & {[\mathrm{VP}} & \mathrm{V} & { }_{n \mathrm{P}} & n & {[} & \sqrt{ } & ]
\end{array}\right]\right]\right]
$$

While it is true that the vast majority of inanimate $\mathrm{V}-\mathrm{N}$ compounds are masculine, there are at least a few attested feminine cases, as shown in (4). ${ }^{7}$

$$
\begin{array}{lll}
\text { [lava-stoviglie } \left._{F}\right]_{F} & \text { [lava-moquette } \left._{F}\right]_{F} & \text { [aspira-polvere } \left._{F}\right]_{F} \\
\text { wash-dishes.FPL } & \text { wash-carpet.F(S/PL) } & \text { suck.up-dust.FS } \\
\text { 'dishwasher' } & \text { 'carpet cleaner' } & \text { 'hoover' }
\end{array}
$$

Admittedly, it is unclear to what extent these rare exceptions are problematic for K18's theory, but we can at least conclude that the proposed generalisation is not absolute. The undeniable statistical skewing in favour of masculine gender that we have seen both here and in $\$ 2.2$ above confirms the intuition that masculine can function as 'unmarked' or

\footnotetext{
${ }^{5}$ As an anonymous reviwer points out, some speakers pronounce overdose as /over'doze/, having reanalysed it as a feminine $e / i$-class noun synchronically derived from Italian dose. Crucially, overdose is feminine even for speakers who retain the consonant-final pronunciation /over'doz/.

${ }^{6}$ This class does in fact exist in Italian, pace Kučerová (2018). See $\S 3$ for details.

${ }^{7}$ Radimský (2006:§3.2.1) lists a few other uncommon cases. Note that (ic) can also be masculine.
} 
'default' (cf. Harris 1991, Sauerland 2003, et seq.). Nonetheless, the theory of K18, as it stands, does not seem to succeed in developing this intuition into a fully-fledged model capable of making the right predictions in a systematic way.

\section{Inflectional Classes and Liberal Nouns}

As we have just seen, there does not seem to be strong empirical evidence for the theory put forward in K18. On the contrary, several facts turn out to be problematic. In this section, we will focus on inflectional classes, their identity conditions, and their interrelations with gender. We will argue that, once the full complexity of the nominal inflection is considered, the distinction between semiconservative and liberal nouns as proposed in K18 cannot be maintained. We will conclude that class is never listed in the lexicon, thereby collapsing the distinction entirely: there are only nouns with fixed, grammatical gender, and nouns with free, interpreted gender.

\subsection{Plurals and the typology of inflectional classes}

A crucial limitation of the entire discussion in K18 is that inflectional classes are defined solely in terms of the vowel of the singular noun ending. As a consequence, only three noun classes are identified, as shown below (cf. Kučerová 2018: 816, ex. 1).
[CL:1]
[CL:2]
[CL:3]
singular in $-o$
singlar in $-a$
singular in $-e$

At no point in K18 are plural nominal endings discussed, even though they are an essential part of the Italian nominal system. In fact, inflectional classes can only be defined in terms of pairings of singular/plural noun endings. Once these are both taken into account, the following typology of six classes comes to light.

1. $\boldsymbol{a} / \boldsymbol{e}$-class ( $-a$ in the singular, and $-e$ in the plural). Only cooccurs with feminine gender, e.g. nonna/nonne ${ }_{F}$ 'grandma(s)', banana/banane ${ }_{F}$ 'banana(s)'.

2. o/i-class (singular in $-o$, plural in $-i$ ). Almost exclusively occurs with masculine gender (e.g. medico/medici ${ }_{M}$ 'doctor(s)', progetto/progetti ${ }_{M}$ 'project(s)'), but there is a single exception: feminine mano/mani $_{F}$ 'hand(s)'.8

3. $\boldsymbol{e} / \boldsymbol{i}$-class. Occurs both with masculine (e.g. padre/padri ${ }_{M}$ 'father(s)', fiume/fiumi ${ }_{M}$ 'river(s)') and feminine (e.g. madre/madri 'mother(s)', parte/parti ${ }_{F}$ 'part(s)').

4. $\boldsymbol{a} / \boldsymbol{i}$-class. Almost exclusively occurs with masculine gender (e.g. poeta/poeti ${ }_{M}$ 'poet(s)', sistema/sistemi ${ }_{M}$ 'system(s)'), but there are two feminine exceptions: $\operatorname{armalarmi}_{F}$ 'weapon(s)', and ala/ali $_{F}$ 'wing(s)'.

5. $\varnothing / \varnothing$-class (invariable or "uninflected" nouns). Occurs both with masculine (e.g. $r e_{M}$ 'king(s)', gorilla ${ }_{M}$ 'gorilla(s)') and feminine gender (e.g. virtù 'virtue(s)', foto $_{M}$ 'photo(s)').

\footnotetext{
${ }^{8} \mathrm{See} \S 4.1$ for putative semiconservative nouns in -o/i like soprano/soprani ${ }_{M / \% F}$ 'soprano(s)'.
} 


\begin{tabular}{llll}
\hline$o$-class [CL:1] & $a$-class [CL:2] & $e$-class [CL:3] & - \\
\hline$o / i$-class (M/F) & $a / e$-class (F) & $e / i$-class (M/F) & $\varnothing / \varnothing$-class (M/F) \\
$o / a$-class (MS/FPL) & $a / i$-class (M/F) & & \\
\hline
\end{tabular}

Table 2: Mapping between Kučerová's (2018) classes and those we identified.

6. o/a-class. Gender is sensitive to number and covaries with it $^{9}$, e.g. uovo ${ }_{M} /$ uova $_{F}$ 'egg(s)', paio $_{M} /$ paia $_{F}$ 'pair(s)'.

That there should be more inflectional classes than the three identified in K18 is not in itself a worrying theoretical issue, because in principle any number of values could be postulated for the feature [CL:_]. However, certain crucial aspects of the theory in K18 are called into question, because the core analytical vocabulary used to formulate its generalisations is empirically inadequate. In light of our discussion, the relevant revisions to the model in (5) would have to be as indicated in Table 2.

Let us consider some important consequences of this shift. First, notice that not all inflectional classes cooccur with both genders. In particular, nouns inflected in the $a / e$ class must be feminine, unlike, for example, those in the $e / i$-class, which can be masculine (e.g. pesce/pesci ${ }_{M}$ 'fish') or feminine (e.g. vite/viti ${ }_{F}$ 'grape vine(s)'). ${ }^{10}$ Therefore, it does not seem to be the case that "any gender feature can combine with any class feature" (Kučerová 2018: 816). This is unexpected and problematic from K18's perspective, because gender and class are represented as independent formal features capable in principle of occurring in any combination, and their purported combinatorial freedom is expressly used as a rationale behind the architecture of K18's model. Deriving these patterns as something more than coincidences or mere lexical regularities would require an altogether different approach, where gender and class are not both represented in the syntax as independent features.

\subsection{Variable class and the typology of liberal nouns}

A more significant issue arises from K18's reliance on post-syntactic default rules to predict the inflectional endings of liberal nouns, which are hypothesised to be stored in the lexicon as bare roots without any gender or class specifications. Depending on the semantics of the referent, liberal nouns can bear either gender value, and this in

\footnotetext{
${ }^{9} o / a$-nouns are masculine in the singular and feminine in the plural, as evidenced by agreement with determiners, adjectives, and participles (see Acquaviva 2008 and references therein). We have included them for the sake of completeness, even though it is debatable whether they form a simple class. Some of them can also have a masculine plural in -i (e.g. braccio $_{M S}$ bracci $_{M P L}-$ braccia $_{F P L}$ 'arm(s)'), suggesting that they are masculine $o / i$-nouns whose root also occurs as a feminine pluralia tantum inflected in a hypothetical, hitherto undiscussed -/a-class (cf. Baggio 2020).

${ }^{10} \mathrm{~A}$ possible solution for this problem may be to collapse the $a / e$-class with the $a / i$-class by analysing them as the feminine and masculine variants, respectively, of a single $a /{ }_{e}^{i}$-class. However, the $a / i$-class includes two feminine nouns: ala ali $_{F}$ 'wing(s)', and arma/armi $_{F}$ 'weapon(s)'. If these are taken at face value, the solution just sketched becomes unavailable. If they are instead dismissed as mere exceptions, one should also by the same token disregard the feminine noun mano/mani $_{F}$ 'hand(s)' in the $o / i$-class, and thus conclude that the $o / i$-class can only include masculine nouns. In either case, it is hard to maintain the claim that every inflectional class can associate with any gender feature.
} 


\begin{tabular}{llcl}
\hline & & CL if M & CL if F \\
\hline figlio $_{M}-$ figlia $_{F}$ & 'child' & $o / i$ & $a / e$ \\
signore $_{M}-$ signora $_{F}$ & 'person' & $e / i$ & $a / e$ \\
collega $_{M}-$-ollega $_{F}$ & 'colleague' & $a / i$ & $a / e$ \\
\hline testimone $_{M}$-testimone $_{F}$ & 'witness' & \multicolumn{2}{c}{$e / i$} \\
\hline
\end{tabular}

Table 3: Nouns with contextually variable gender (liberal and semiconservative)

turn dictates the inflectional ending in a completely predictable way. According to the Vocabulary Insertion rules postulated in K18, in the absence of a valued [CL] feature nouns with [GEN:M] inflect in the $o / i$-class, and those with [GEN:F] in the $a / e$-class. This approach works correctly for liberal nouns such as figli-o/i ${ }_{M}-$ figli-a/e $_{F}$ 'child(ren)', as amply discussed in K18, but turns out to be too narrow once we consider that not all liberal nouns inflect in this way. The two sets of problematic cases, signore-type nouns and collega-type nouns, are now discussed in turn.

First, consider signore/signori ${ }_{M}$-signora/signore $_{F}$ 'person(s)', which inflects as expected in $-a / e$ when feminine, but takes $e / i$-endings when masculine. K18's account incorrectly predicts the masculine singular to be *signoro.

Second, there are nouns with an invariant gender-insensitive singular form, but a gender-sensitive plural ending. For example, singular colleg $a_{M / F}$ 'colleague' can be both masculine or feminine, and an agreeing determiner or adjective would be required for disambiguation. Because plural endings are systematically set aside in K18, the approach pursued in K18 will simply stop here and characterize collega as a semiconservative noun of the " $a$-class", predicting a single gender-invariant plural form. This is in fact the position explicitly adopted for e.g. $\operatorname{artista}_{M / F}$ 'artist', which inflects in the same way as collega. As soon as we broaden our focus, however, it emerges that neither collega nor artista behave as predicted, because they take inflectional endings of two distinct classes depending on the gender: compare for example colleghi $i_{M}$ (a/i-class) vs. colleghe ${ }_{F}$ (a/e-class) 'colleagues'.11

To summarise, in addition to liberal nouns that inflect in $-o / i$ and $-a / e$ (e.g. figlio 'child'), there are two additional subtypes that are left unaccounted for in K18: those that take masculine $-e / i$ and feminine $-a / e$ (e.g. signore 'person'), and those that take masculine $-a / i$ and feminine $-a / e$ (e.g. collega 'colleague'). All these cases contrast with semiconservative nouns in $-e / i$, which have the same inflectional ending regardless of gender, such as testimon-e/i $i_{M / F}$ 'witness(es)'. Table 3 summarises the empirical landscape (see Acquaviva 2009: 53-54 for more details, and $\$ 4.1$ below for soprano-type nouns).

As it currently stands, the system in K18 both undergenerates, because it predicts the impossibility of signore- and collega-nouns, and overgenerates, because it predicts the attestation of semiconservative nouns in $-a / e$, in $-o / i$, and in $-a / i$, contrary to fact. Even more problematically, the facts in Table 3 lead K18's view to run into a timing paradox. On the one hand, it is maintained that semantically interpreted gender (e.g. in

\footnotetext{
${ }^{11}$ The $h$ in the plural forms is purely orthographical, and is used to indicate that the preceding $g$ is to be pronounced as velar $/ \mathrm{g} /$, rather than palato-alveolar $/ \mathrm{d}_{3} /$.
} 
signor-e/i ${ }_{M}-$ signor-a/e $_{F}$ 'person(s)') is only assigned when the DP phase is Transferred to the CI interface (see $\$ 4.2$ below for details). On the other, it is claimed that class is only ever assigned in the lexicon: e.g. the information that singular masculine signore terminates with $-e$ (rather than $-o$ or $-a$, cf. medico ${ }_{S M}$ 'doctor' and poeta ${ }_{S M}$ 'poet') must

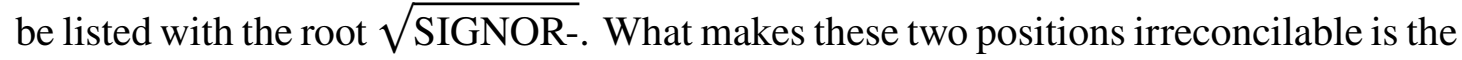
fact that the class of $\sqrt{\text { SIGNOR- }}$ depends additionally on contextually assigned gender: $e / i$ for masculine, $a / e$ for feminine. In other words, information supposedly encoded in the lexicon (presyntactically) turns out to be defined only parasitically on information that is created at the interface level (postsyntactically).

In order to maintain at least the outlines of K18's theory, one could stipulate more abstract inflectional classes that specify a different ending for each gender/number combination, e.g. a hypothetical ${ }_{a / e}^{e / i}$ class for signore, and ${ }_{a / e}^{a / i}$ for collega. Concretely, these could be formalised as non-decomposable or "atomic" values of [CL]. In this case, however, almost any combination of inflectional endings would be predicted to be possible, and there would be no principled way to rule out, e.g., a hypothetical noun *colleda of class $\begin{gathered}a / i \\ i / o\end{gathered}$ that inflects like collega/ $i_{M}$ when masculine, but as $*{ }^{*}$ colledi $_{F S} /{ }^{*}$ colledo $_{F P L}$ when feminine. This is not in itself an issue, but it becomes one as soon as one considers the data in Table 3. As Table 3 indicates, every four-way inflectional paradigm can be reduced to a combination of the familiar two-way classes (namely, $o / i, a / e, a / i, \ldots$ ). These considerations speak against a model with atomic four-way inflectional classes, and suggest instead a model where higher-order feature values are decomposed into combinations of simpler ones by way of "conditional feature specifications" of the type exemplified in (6).

$$
\text { [ CL: } \left.\left\{\begin{array}{l}
e / i \text { iff } \mathrm{M} \\
a / e \text { iff } \mathrm{F}
\end{array}\right\}\right] \quad \text { Assign to [CL] the value } e / i \text { iff [GEN:M] and } a / e \text { iff [GEN:F] }
$$

Aside from methodological worries with the introduction of a novel mechanism of feature valuation, this would raise concerns about overgeneration. In particular, we would still expect to see impossible liberal nouns inflecting in e.g. $\left\{\begin{array}{l}o / i \text { iff } \mathrm{M} \\ e / i \text { iff } \mathrm{F}\end{array}\right\}$, and many other unattested combinations. Admittedly, this issue is by no means unique to K18's theory, but there are some recent approaches that are able to derive the possible and impossible patterns in a principled fashion (see in particular Lampitelli 2010, 2014). To take stock, the data in Table 3 forces us to either abandon K18's theory, or to revise it by adopting overly powerful tools that raise familiar concerns about theoretical economy and overgeneration, and arguably miss some important generalisations.

For the sake of the argument, let us momentarily set these concerns aside and assume some version of (6). The variation among liberal nouns reported in Table 3 suggests that these are lexically specified for inflectional class. However, these nouns are modelled in K18 as bare roots, which by definition cannot carry information such as (6). To maintain K18's view, one could either bite the bullet and stipulate that roots can carry class features, or simply suggest that these roots are listed in the lexicon in combination with a categoriser $n$ bearing CL features. Either way, this strategy would collapse the distinction between semiconservative and liberal nouns, because the former are identified as those whose class is encoded as part of their lexical specification (via $n$ ). If liberal nouns are 
also specified for class, the difference between the two evaporates, undermining K18's three-way classification of Italian nouns.

At this point, we can only envisage one possible rescue strategy. With conditional class specifications like (6) one could still choose one of the patterns in Table 3, e.g. figli-o/i $_{M}-$ figli-a/e $_{F}$ 'child(ren)', as representative of true liberal nouns whose ending is determined by default insertion rules applying to an unvalued [CL: \{\}$]$ feature, in contrast with e.g. signor-e/ $i_{M}$-signor-a/e $e_{F}$ 'person(s)'. The latter would be a semiconservative noun specified in the lexicon with the feature [CL: $\left.\left\{\begin{array}{l}e / i \\ a / e\end{array}\right\}\right]$ (or [CL: $\left.\left.\{e / i\}\right]\right)^{12}$, alongside semiconservative nouns that bear non-conditional (i.e. gender-insensitive) class features, such as [CL:e/i] in testimon-e/i ${ }_{M / F}$ 'witness(es)'. An attempt to rescue the liberal vs. semiconservative distinction in this way comes with the high theoretical cost of positing conditional feature values, with the empirical issue of overgeneration arising from the model's power, and with the ad hoc stipulation that only one of the patterns of Table 3 involves true bare roots. This is all the more problematic since the phenomenon that they point towards, on the face of it, is exactly the same: i.e. inflectional class depends both on the root and on its gender.

A much more natural approach to the issue of gender-dependent inflectional classes and the ensuing "timing paradox" would be to abandon the idea that inflectional class is encoded in the lexicon, in favour of a postsyntactic approach to the PF interface (as proposed in various guises by e.g. Oltra-Massuet 1999, Oltra-Massuet and Arregi 2005, Embick and Halle 2005, Embick 2010, Lampitelli 2010, 2014, Armelin 2014, Kramer 2015). At this derivational stage, all the relevant information to determine the appropriate inflectional ending is available: the identity of the root, and the value of gender established at Transfer (or determined lexically, for conservative nouns). Reanalysing inflectional class as a postsyntactic matter of the PF interface would also immediately solve an outstanding mystery in K18's system: as Kučerová (2018) herself admits in $\mathrm{K} 18, \mathrm{CL}$ is a sui generis syntactic feature unlike any other, because it is completely inert to syntactic operations. Additionally, CL is also invisible to the semantic computation at LF. In other words, the only linguistic module whose computations seem to care about CL features is the PF interface. Needless to say, this alternative approach would also collapse the distinction between liberal and semiconservative nouns, as they would both lack gender and class in the lexicon.

To summarise, however one may wish to approach cases like signor-e/ $i_{M}$-signor$a / e_{F}$ 'person(s)' and colleg-a/i ${ }_{M}$-colleg-a/e ${ }_{F}$ 'colleague(s)', the theory put forward in K18 needs substantial revisions to accommodate all the data. In particular, once plural nouns are taken into account and careful attention is paid to (un)attested inflectional patterns, gender and class turn out to be intricately linked in ways that threaten to undermine K18's model, which treats gender and class as completely independent features. Further, it becomes doubtful that the liberal vs. semiconservative distinction can still be upheld, and that the idea of [CL] as a syntactic feature present in the lexicon is tenable. The interested reader is referred in particular to Acquaviva (2009), Passino (2009), and Lampitelli $(2010,2014)$ for attempts to explain the complex phenomena we have been hinting at. Regrettably, the fact that K18 does not include plural forms within its purview

\footnotetext{
${ }^{12}$ Note how this approach, like K18's original model, faces the issue of explanatory overdetermination, because some endings (e.g. $-a / e$ ) are both default exponents, and exponents of a [CL] feature.
} 
means, in our view, that the surface of a rich and complex empirical landscape is barely scratched.

\section{Contextual Gender Valuation at Transfer}

Our final set of objections revolves around the use that K18 makes of Phase Theory, according to which semantically interpreted gender values enter the syntactic representation only when a DP phase undergoes Transfer. §4.1 points out several issues of K18's account of gender mismatches in terms of the timing of Transfer. $\$ 4.2$ then argues that the idea of contextual valuation itself does not hold water, because not enough information about the context is available when the local phase is transferred.

\subsection{Gender mismatches}

Consider the following paradigm, displaying the phenomenon of 'gender mismatch', which features prominently in the discussion in K18. ${ }^{13}$
a. Il sopran-o è andat-o a casa. the.MS soprano-oil.S is gone-MS at home 'The (male or female) soprano went home.'
b. La sopran-o è andat-a a casa. the.FS soprano-ori.S is gone-FS at home 'The female soprano went home.'
c. Il sopran-o è andat-a a casa. the.MS soprano-ori.S is gone-FS at home
'The female soprano went home.'

In the first sentence, (7a), the subject DP is compatible with a male referent and, for most speakers, also with a female referent. According to the model in K18, this is because these speakers list soprano as a conservative noun in their lexicon: regardless of the intended referent, its class is fixed as [CL:o/i], and its gender as (uninterpretable) [GEN:M]. Speakers who prefer instead option (7b) with female referents store the same noun as a semiconservative entry, with fixed class [CL:o/i] but free contextually assignable gender. As a result, in K18's theory the apparent gender mismatch of (7b) is analysed away in terms of semiconservativity: gender features are feminine throughout, even if this can be covered up by the inflectional class of the noun.

The third option, $(7 \mathrm{c})$, is surprising, and appears to violate standard rules of subjectverb agreement. In order to explain this, it is proposed that contextual gender valuation can happen either before or after the syntactic representation is sent to the morphology. More specifically, K18 makes a distinction between Spell-Out, the derivational stage at which all narrow syntactic operations within a phase are completed, and Transfer, the subsequent derivational stage at which the phase undergoes labelling, contextual gender valuation, and is sent to the CI interface. Further, it is assumed that the operations

\footnotetext{
${ }^{13}$ We gloss theme vowels as CL.NUM on nouns, to be agnostic about the underlying gender value, and as GEN.NUM elsewhere (adjectives, determiners, etc...), where gender is predictable from class.
} 
applying at Transfer are still able to modify the syntactic representation itself. In particular, once a gender feature is valued contextually, its value is visible to any subsequent syntactic operation. With this machinery in place, K18 further proposes that phases, crucially including DPs, can be sent to the PF interface for morphological interpretation either at the stage of Transfer, after labelling and contextual valuation, or before Transfer, at the stage of Spell-Out. In the former case, gender features valued contextually at Transfer will be visible to the morphology, but in the latter case the morphology will only be able to see unvalued gender features, which it realises as default masculine by a last resort rule (cf. e.g. Noyer 1998, and more recently Preminger 2014). If the noun soprano can be semiconservative, the second option can now explain the pattern in (7c). Since the DP reaches Spell-Out and is sent to PF before Transfer and contextual valuation, its still unvalued gender feature is spelled out as default masculine. After Transfer and contextual valuation, however, its gender value will be visible to the remaining syntactic computation and morphologically realised, e.g. on the agreeing participle. Once again, this means that for K18 'gender mismatch' is a mere artifact of Spell-Out: gender features in the syntax are uniformly feminine.

The first issue with this account is that it predicts the existence of a near-identical pattern to (7), where semiconservative nouns in the $a / e$-class have a male (or non-female) referent and control masculine agreement. In particular, just as speakers seem to vary in listing the nouns soprano $_{(M)}$ 'soprano' and chirurgo $_{(M)}$ 'surgeon' either with [CL: o/ $i$, GEN:M] (conservative) or with [CL: $o / i]$ only (semiconservative), we should expect there to be nouns exhibiting a parallel variation between [CL: $a / e$, GEN:F] and [CL: $a / e]$, e.g. sentinella $a_{(F)}$ 'sentinel' and spia ${ }_{(F)}$ 'spy'. In the latter case, we would predict the "mixed" patterns $* l_{M}$ spia $_{a / e} \grave{e}$ andato $_{M}$ a casa ('the (male) spy went home', intended non-female referent, DP sent to PF at Transfer) and *lo ${ }_{M} \operatorname{spia}_{a / e} \grave{e}$ andata $_{F} a$ casa ('the female spy went home', intended female referent, DP sent to PF before Transfer), by analogy with (7b) and (7c) respectively. Interestingly, the prediction is not met, nor can any semiconservative $a / e$-nouns be found at all (cf. $\S 3$ above). This data point is in direct contradiction with Kučerová 2019, where feminine $a / e$-nouns are claimed to permit semiconservative variants with contextual masculine gender. As far as we can ascertain, this is factually incorrect (cf. Baggio 2020), and the examples provided (i.e. $*_{i l_{M}}$ soprana $_{a / e}$ on p. 129 and $*^{*}$ sentinella $_{a / e}$ coraggioso $_{M}$ 'courageous sentinel' on p. 131) are sharply rejected by all speakers. ${ }^{14}$

In addition to the aforementioned worries about empirical adequacy and overgeneration, the pattern in (7b)-(7c) is in fact expected to arise with all semiconservative nouns, especially the prototypical ones in -e/i (e.g. testimone ${ }_{M / F}$ 'witness', cf. $\S 3$ above). As a result, the model in K18 also wrongly predicts the grammaticality of (8) by analogy with $(7 \mathrm{c})$.

(8) *Il testimon-e è andat-a a casa.

the.MS witness-eri.S is gone-FS at home 'The female witness went home.'

\footnotetext{
${ }^{14}$ The paper mentions a Google search as the only evidence for the acceptability of *sentinella coraggioso. Our attempt to replicate this (while taking any misparsings into account) has yielded no results. It is reasonable to conclude that we are dealing with a factual inaccuracy, rather than speaker variation.
} 
A more substantial challenge for K18's approach comes from DP-internal gender mismatches on agreeing modifiers. As Kučerová (2018: 821) herself notes, there are cases where adjective and noun appear to bear different genders, as in rrava $_{F}$ avvocato $_{M}$ 'good female lawyer'. Essentially the same explanation is given to this example as to (7b) above: speakers who accept it in their grammar have no gender mismatch at all, but rather treat avvocato as a semiconservative noun with a lexically fixed [CL:o/ $i$ ] feature in and a free gender feature valuable contextually. However, this cannot be the whole story, given the following paradigm (pace Kučerová 2018: 821, fn. 19. See Baggio 2020: 30 for this paradigm with primo ministro 'prime minister').

$$
\begin{aligned}
& \text { a. il }[\text { brav-o }[\text { sopran-o legger-o ] ] } \\
& \text { the.MS good-MS soprano-ori.S light-MS } \\
& \text { 'the good ((fe)male) coloratura soprano' } \\
& \text { b. la }[\text { brav-a/*-o }[\text { sopran-o legger-o/*-a ] ] } \\
& \text { the.FS good-FS/*-MS soprano-ori.S light-MS } / *_{-F S}^{-F} \\
& \text { 'the good female coloratura soprano' }
\end{aligned}
$$

(9a) is the baseline case, where soprano behaves like a conservative masculine $o / i$-class noun and is accompanied by the structurally high adjective bravo 'good' and structurally low leggero 'light (lit.)' (cf. Scott 2002, Cinque 2010). Against that, (9b) provides the crucial data on DP-internal agreement missing from the discussion in K18. It demonstrates that when soprano has a female referent and takes a feminine article, high adjectives must be feminine, covarying in gender with the article, while low adjective must remain masculine (cf. Steriopolo and Wiltschko 2010 and Pesetsky 2013: 35-50 for Russian). First of all, this data shows that the noun soprano cannot be semiconservative as proposed in K18. Consider why. If it could be listed as a semiconservative $o / i$-noun with gender valued contextually, the unattested pattern $* \mathrm{D}_{F}>\operatorname{Adj}_{F}>\operatorname{Adj}_{F}>\mathrm{N}_{o / i}$ would be predicted to be grammatical at least to those speakers who accept (7b), contrary to fact. On the other hand, the attested pattern $\mathrm{D}_{F}>\operatorname{Adj}_{F}>\operatorname{Adj}_{M}>\mathrm{N}_{o / i}$ would remain entirely unexpected. More generally, this data shows that the notion of semiconservativity as it stands in K18 cannot explain the relevant phenomenon, which may involve instead a real featural mismatch between the lower and the higher layers of the DP (perhaps due to a feminising head à la Pesetsky 2013, as suggested in Acquaviva 2019 and Baggio 2020; cf. also Wechsler and Zlatić 2003, Steriopolo and Wiltschko 2010, Matushansky 2013, Landau 2016 for alternatives). In turn, this casts doubt on K18's claim that there are semiconservative nouns in the $o / i$-class at all, because $o / i$-nouns are all masculine (mano 'hand' being the sole exception), and those that allow feminine morphology only do so in the form of gender mismatch as discussed for soprano here.

Let us briefly consider whether the semiconservativity-based account of K18 can be maintained by postulating an additional phase boundary between the two adjectives in (9b). In particular, K18 proposes that contextual gender valuation targets the phase head $\mathrm{D}^{0}$, where determiners are: then, if another phase intervenes "midway" between the article and the noun, the contextually assigned gender value would only "percolate" down to the higher adjective, and the lower adjective and noun would be realised as masculine by default. However, appealing to an additional phase ends up making once again the incorrect predictions. First, it is essential to assume the DP-internal phase 
to be optional, or else contextually assigned gender could never percolate down to the noun to affect its morphology, and liberal nouns like figlio 'child' would be predicted to invariably end in default $-o / i$. However, as soon as the DP-internal phase becomes optional, nothing can rule out the ungrammatical pattern $* \mathrm{D}_{F}>\operatorname{Adj}_{F}>\operatorname{Adj}_{F}>\mathrm{N}_{o / i}$ in (9b), which was the reason for positing an additional phase in the first place.

Finally plural forms present a further problem for K18. While singular cases of gender mismatch are indeed possible, their plural counterparts are not: contrast singular $l a_{F}$ soprano $_{o / i}$, as in (7b), with the outrightly ungrammatical plural $* l e_{F}$ soprani $_{o / i}$ (cf. Acquaviva 2019). This essential data point is overlooked in K18, because of the exclusive focus on singular forms, yet it poses a difficult issue for a view where gender mismatches are analysed in terms of semiconservativity. In this regard, there is once again a stark contrast between nouns like soprano, completely disallowing feminine plurals, and the well-behaved semiconservative nouns of the $e / i$-class. The latter show no unexpected paradigm gaps, as evidenced by the contrast between $* l e_{F}$ soprani $_{o / i}$ and the perfectly grammatical le $e_{F}$ testimoni $e_{e}$ 'the female witnesses'.

Drawing some conclusions, it is clear that the phenomena of gender mismatch and of semiconservativity should be kept completely separate, for two reasons. First, the morphosyntactic behaviour of semiconservative nouns in $-e / i$ (e.g. testimone) and the behaviour of $o / i$-nouns like soprano differ significantly in all the cases discussed. Second, K18's semiconservativity-based account makes the wrong predictions as soon as one looks beyond its reduced sample of unmodified singular DPs.

\subsection{Gender cannot be contextually valued locally}

The final issue we wish to raise concderns the proposal in K18 that interpreted gender enters syntax from context when a phase is transferred. We argue that the idea does not work out in the syntactic framework assumed, because contextual gender valuation needs to be able to look far beyond the local domain defined by the relevant phase. This issue, in our view, undermines K18's contextual valuation model on a fundamental level.

Let us start with reviewing the semantic assumptions K18 makes.

Following Heim 2008, it is assumed that interpretable gender features, which according to K18 always come from contextual valuation, introduce a presupposition on the value of the index. The denotations for masculine and feminine are the following.

$$
\begin{aligned}
& \text { a. } \llbracket\left[\mathrm{GEN}: \mathrm{M}_{i}\right] \rrbracket^{w, g}=\lambda x_{e}: g(i) \text { is a person in } w \cdot x \\
& \text { b. } \llbracket\left[\mathrm{GEN}: \mathrm{F}_{i}\right] \rrbracket^{w, g}=\lambda x_{e}: g(i) \text { is female in } w \cdot x
\end{aligned}
$$

(adapted from Kučerová 2018:828) $)^{15}$

Notice that the masculine feature only presupposes humanness, a common assumption in the literature (e.g. Heim 2008, Spathas and Sudo 2020, Sudo and Spathas 2020; see also Percus 2011). This is crucial to account for the elsewhere nature of masculine, as exemplified in (11), where the speaker is ignorant about the referent's gender.

\footnotetext{
${ }^{15}$ As an anonymous reviewer points out, the notation in K18 is unusual, as the lambda term is followed by '.' and the presupposition is followed by ':'. Accordingly, we have revised the formulas (originally ex. (19) of K18) to conform to the standard conventions from Heim and Kratzer (1998).
} 
Chi è il tu-o figli-o preferit-o?

who is the.MS your-MS child-ori.S favorite-MS

'Who is your favorite child? (son or daughter, regardless)'

Contrast this with its feminine counterpart (12) where only daughters are relevant.

Chi è la tu-a figli-a preferit-a?

who is the.FS your-FS child-a/e.S favorite-FS

'Who is your favorite daughter?'

To complicate the picture, masculine nouns do not always behave gender-neutrally: when the referent is known to be female, the masculine version of a liberal noun cannot be used, which the semantics in (10) cannot account for by itself. To this end, interpreted masculine and feminine features are commonly assumed to compete with each other: whenever the feminine version of a sentence can be used, it must be used.

In order to formalise this idea, K18 adopts a version of Heim's (1991) principle of Maximize Presupposition, as quoted below. In this characterization, however, some central issues are left liable to equivocation.

'Heim's (1991) Maximize Presupposition [...] asserts that if there is a presupposition associated with a structure and if this presupposition can be grammatically realized, it must be realized.'

(Kučerová 2018: 829)

First, Maximize Presupposition (henceforth MP), as standardly formulated, is not about morphosyntactic realisation, but presuppositional strength. For example, if the presence of a suffix is associated with a weaker presupposition than its absence and the relevant conditions are met, the principle will disfavour use of the suffix, as discussed at length in the literature on number (e.g. Sauerland 2003, 2008, Sauerland, Anderssen, and Yatsushiro 2005). Secondly, the principle does not blindly prefer the presuppositionally stronger alternative. Rather, it does so when the alternative's presupposition is satisfied. This is in fact a crucial condition in understanding why the idea of contextual gender valuation at the local phase level is problematic, so let us delve into it.

First, MP is standardly stated as in (13).

(13) Sentence $S$ is infelicitous in context $c$ if there is an alternative $S^{\prime}$ such that

a. the assertive meanings of $S$ and $S^{\prime}$ are contextually equivalent in $c$;

b. $\quad S^{\prime}$ has a stronger presupposition than $S$; and

c. the presupposition of $S^{\prime}$ is satisfied in $c$.

To see how this works concretely, consider (14). Both sentences are expected to be semantically coherent and assert the very same proposition. When the subject refers to an individual who is known in the context to be a girl, then only (14a) is felicitous. This is because, according to the assumption that masculine only presupposes humanness, the presupposition of (14a) is both stronger than (14b) and it satisfied in the context. MP correctly predicts (14b) to be infelicitous. ${ }^{16}$

\footnotetext{
${ }^{16}$ Note that in K18's semantic representation, given in (10), we need to understand is female as is a female person (or alternatively, is a person as is a gendered creature) in order for MP to apply.
} 
a. Mi-a figli-a ha sete.

my-FS child-a/e.s has thirst

'My daughter is thirsty.' b. Mi-o figli-o ha sete. my-MS child-ori.s has thirst 'My child/son is thirsty.'

Now consider a context where the subject refers to an individual known to be a boy. The presupposition of (14a) would not be satisfied, and (14b) would become felicitous. This creates the impression that masculine gender denotes maleness.

Gender-neutral uses of masculine also follow from this approach. Consider again (11) and its feminine alternative (12), which presupposes the referent of the DP to be female. In a context where the speaker does not know the referent's gender, this presupposition is not satisfied and (11) is correctly predicted to be felicitous.

Furthermore, crucially for us, MP is not always computed at the DP level, but it may interact with operators higher up in the structure, as demonstrated in (15).

[Ogni genitore $]_{i}$ crede che il propri-o ${ }_{i}$ figli-o sia intelligente. every parent believes that the.MS self-MS child-oit.S is intelligent 'Every parent believes that his child is intelligent.'

In this example, the possessive pronoun inside il proprio figlio can be bound by ogni genitore in the matrix clause. Under this interpretation, the sentence is acceptable even if some of the parents only have daughters. This is accounted for by applying MP at the matrix level, where (15) competes with the feminine version in (16).

[Ogni genitore $]_{i}$ crede che la propri-a ${ }_{i}$ figli-a sia intelligente. every parent believes that the.FS self-FS child-a/e.S is intelligent 'Every parent believes that his daughter is intelligent.'

The sentence in (16) presupposes that every parent has a daughter. According to MP, any context where every parent's child is known to be a girl satisfies this presupposition and makes the alternative in (15) infelicitous. However, this presupposition fails as soon as even one parent's child is known to be a boy, rendering (15) felicitous.

Crucially, it is not possible in (15) to decide which gender to use in the context given at the level of the DP il proprio figlio. This can only be determined at a global level, as the possessive pronoun proprio may or may not be bound when embedded in a larger structure. And if proprio is bound by a universal quantifier, as in our example, the DP that contains it does not refer to a single individual at all. Deciding at the DP level whether the context satisfies the femaleness presupposition is impossible.

Further, the structural distance from the binder is in principle unbounded. Whether Transfer occurs as soon as the DP is complete (cf. Chomsky's 2000 strong PIC), or is delayed until the next phase up (e.g. Chomsky's 2001 weak PIC), (17) demonstrates that the distance between binder and bindee can extend too far beyond the local phasal domain for any version of Phase Theory to cover within a single round of Transfer.

$$
\begin{aligned}
& \text { [Nessun genitore }]_{i}\left([ _ { \nu \mathrm { P } } ) \text { dubitava } \left[_ { \mathrm { CP } } \text { che } 1 ^ { \prime } \text { indovino } { } _ { { } _ { v \mathrm { P } } } \text { possedesse } \left[_{\mathrm{DP}}\right.\right.\right. \text { la } \\
& \text { no parent doubted that the soothsayer possessed the } \\
& \text { capacità }\left[_ { \mathrm { PP } } \text { di } \left[_ { \nu \mathrm { P } } \text { sapere } \left[_ { \mathrm { DP } } \text { il nome } \left[_ { \mathrm { PP } } \text { de- } \left[_ { \mathrm { DP } } - \text { lla persona } \left[_{\mathrm{CP}}\right.\right.\right.\right.\right.\right. \text { che } \\
& \text { capacity of knowing the name of- -the person that }
\end{aligned}
$$




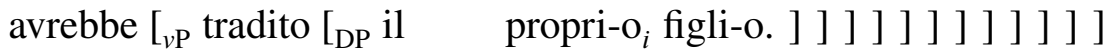

would betray the.MS self-MS child-ori.S

'No parent doubted the soothsayer's capacity to know the name of the person who was going to betray their child.'

At least eleven projections that are typically considered phases intervene between the quantifier and the bound pronoun in (17): ${ }^{17}$ four DPs, three (transitive) $v$ Ps, two (finite) CPs, and two PPs (cf. Chomsky 2001, 2008, Bošković 2004a,b, 2005, Abels 2003, Citko 2014). It seems clear that no relaxation of the timing of Transfer could account for the non-local nature in the computation of gender presuppositions.

This is part of a more general issue for the phase-based theory assumed in K18. In more technical terms, the meanings in (10) are relativised to an assignment and a world parameter, $g$ and $w$. (15)-(17) above show that at the DP level $g$ might not be fixed yet, as a binder higher in the structure could quantify over assignments that output different values for $i$. There is simply no way of knowing which $g$ to use at the local level. The same issue arises with $w$, as (18) exemplifies: with a modal higher in the structure, gender valuation is relative to quantified possible worlds, and there is no way to determine which possible worlds to consider at the level of the local DP phase.
Maria crede che tu sia un genitore, e si chiede se tu-a figli-a
Maria believes that you are a parent, and self asks if your-FS child-ÆS
vive a Londra.
lives in London
'Maria thinks you're a parent, and wonders if your daughter lives in London.'

Sentence (18) presupposes that Maria believes the addressee to have a daughter, ${ }^{18}$ indicating that the gender presupposition triggered by feminine marking must be evaluated relative to Maria's belief worlds. If gender valuation occurred as soon as the DP phase was transferred, it could never be relativized to possible worlds introduced by an attitude predicate in a higher position in such a way. ${ }^{19}$

Given these considerations, we conclude that constructing a theory of contextual gender around the notion of valuation at the phase level is not theoretically feasible.

\section{Concluding remarks}

The theory of gender and inflectional class put forward in K18 faces many empirical and theoretical challenges. We briefly review our main concerns. In $\S 3$ we have suggested that the lexical distinction between semiconservative and liberal nouns collapses under

\footnotetext{
${ }^{17}$ For ease of readability, the bracketing in (17) ignores head-movement. Note that the lowest, most conservative count permitted within K18's theory could exclude PPs, but trivially not DPs, merely pushing the number of structurally intervening phases down to nine.

${ }^{18}$ As an anonymous reviewer points out, the problem in (18) only arises from the de dicto interpretation of tua figlia. Nonetheless, the first conjunct can only be naturally construed with an inference that the addressee is not a parent, due presumably to the verb crede (cf. Percus 2006, Chemla 2008, among others), making the de dicto interpretation for tua figlia the only natural one available.

${ }^{19}$ Once again, the structural distance between the DP and the modal expression introducing relevant possible worlds seems to be indefinitely large, cf. (17). Examples are omitted for reasons of space.
} 
thorough empirical scrutiny of inflectional classes, which should reasonably be relegated to the postsyntactic (PF) component (cf. Acquaviva 2009, Passino 2009, Lampitelli $2010,2014)$. We cast further doubt on semiconservativity in $\$ 4.1$, where we argue that using this notion to explain away gender mismatch phenomena generates incorrect predictions. Gender mismatch, it seems, does involve a true feauture discrepancy, formaliseable in terms of a feminizer projection (e.g. KP in Pesetsky 2013, Acquaviva 2019, Baggio 2020), or different feature "flavours" (e.g. INDEX vs. CONCORD features in Landau 2016). Finally, in $\$ 4.2$ we have rejected K18's attempt to derive the interpretable vs. uninterpretable gender distinction from the notion of contextual valuation at Transfer. For many competing alternatives we once again refer the reader to the literature (Pesetsky 2013, Kramer 2015, Puškar 2015, Baggio 2020, Spathas and Sudo 2020, Sudo and Spathas 2020). Even though we cannot do justice to the complexity of these issues, we hope to have made a convincing case that the model advanced in K18 is not fit for purpose.

\section{References}

Abels, Klaus. 2003. Successive cyclicity, anti-locality, and adposition stranding. Doctoral Dissertation, Univeristy of Connecticut, Storrs.

Acquaviva, Paolo. 2008. Lexical plurals. Oxford: Oxford University Press.

Acquaviva, Paolo. 2009. The structure of the Italian declension system. In Selected proceedings of the 6th Décembrettes: Morphology in Bordeaux, ed. Fabio Montermini, Gilles Boyé, and Jesse Tseng. Somerville, MA: Cascadilla Proceedings Project.

Acquaviva, Paolo. 2019. Categorization as noun construction: Gender, number, and entity types. In Gender and noun classification, ed. Éric Mathieu, Myriam Dali, and Gita Zareikar, 41-63. Oxford: Oxford University Press.

Armelin, Paula. 2014. Classifying nominals in Brazilian Portuguese: A unified account for gender and inflectional class. In Complex Visibles Out There. Proceedings of the Olomouc Linguistics Colloquium 2014: Language Use and Linguistic Structure, 6782.

Baggio, Pietro. 2020. Getting rid of MASC: The encoding of gender in italian. Ms., Queen Mary University of London.

Bošković, Željko. 2004a. Be careful where you float your quantifiers. Natural Language and Linguistic Theory 22:681-742.

Bošković, Željko. 2004b. Object shift and the clause/PP parallelism hypothesis. In Proceedings of WCCFL 23, ed. B. Schmeiser, V. Chand, A. Kelleher, and A. Rodriguez, 101-114. Somerville, MA: Cascadilla Press.

Bošković, Željko. 2005. On the locality of left branch extraction and the structure of NP. Studia Linguistica 59:1-45. URL https://doi .org/10.1111/j .1467-9582. 2005.00118.x.

Chemla, Emmanuel. 2008. An epistemic step for anti-presuppositions. Journal of Semantics 25:141-173. URL http://dx.doi.org/10.1093/jos/ffm017.

Chomsky, Noam. 2000. Minimalist inquiries: the framework. In Step by step: Essays on minimalist syntax in honor of Howard Lasnik, ed. R. Martin, D. Michaels, and Juan Uriagereka, 89-115. Cambridge, MA: MIT Press. 
Chomsky, Noam. 2001. Derivation by phrase. In Ken Hale: A life in language, ed. Michael Kenstowicz, 1-52. Cambridge, MA: MIT Press.

Chomsky, Noam. 2008. On phases. In Foundational issues in linguistic theory: Essays in honor of Jean-Roger Vergnaud, ed. Robert Freidin, Carlos P. Otero, and Maria Luisa Zubizarreta, 133-166. Cambridge, MA: MIT Press. URL https: //doi.org/10.7551/mitpress/9780262062787.003.0007.

Cinque, Guglielmo. 2010. The syntax of adjectives: A comparative study. Cambridge, MA: MIT Press.

Citko, Barbara. 2014. Phrase theory: An introduction. Cambridge: Cambridge University Press. URL https://doi.org/10.1017/CB09781139644037.

Embick, David. 2010. Localism versus globalism in morphology and phonology. Cambridge, MA: MIT Press.

Embick, David, and Morris Halle. 2005. On the status of stems in morphological theory. In Romance languages and linguistic theory 2003: Selected papers from 'Going Romance' 2003, Nijmegen, 20-22 november, ed. Twan Geerts, Ivo von Ginneken, and Haike Jacobs, 37-62. Amsterdam: Benjamins.

Ferrari, Franca. 2005. A syntactic analysis of the nominal systems of Italian and Luganda: How nouns can be formed in the syntax. Doctoral Dissertation, New York University.

Ferrari-Bridgers, Franca. 2008. A unified syntactic analysis of Italian and Luganda nouns. In The Bantu-Romance connection, ed. Cécile de Cat and Katherine Demuth, 239-258. Amsterdam: Benjamins.

Harris, James W. 1991. The exponence of gender in Spanish. Linguistic Inquiry 22:2762.

Heim, Irene. 1991. Artikel und Definitheit. In Semantik: Ein internationales Handbuch der zeitgenössischen Forschung/Semantics: An international handbook of contemporary research, ed. Arnim von Stechow and Dieter Wunderlich, 487-535. Berlin: de Gruyter.

Heim, Irene. 2008. Features on bound pronouns. In Phi theory: Phi-features across modules and interfaces, ed. Daniel Harbour, David Adger, and Susana Bejar, 35-56. Oxford: Oxford University Press.

Heim, Irene, and Angelika Kratzer. 1998. Semantics in generative grammar. Oxford: Blackwell.

Kramer, Ruth. 2015. The morphosyntax of gender. Oxford: Oxford University Press.

Kučerová, Ivona. 2018. $\phi$-features at the syntax-semantics interface: Evidence from nominal inflection. Linguistic Inquiry 49:813-845. URL https://doi .org/10. 1162/ling_a_00290.

Kučerová, Ivona. 2019. The double life of gender and its structural consequences: A case study from Standard Italian. In Gender and noun classification, ed. Éric Mathieu, Myriam Dali, and Gita Zareikar, 119-135. Oxford: Oxford University Press.

Lampitelli, Nicola. 2010. Nounness, gender, class and syntactic structures in Italian nouns. In Romance languages and linguistic theory 2008: Selected papers from 'Going Romance' Groningen 2008, ed. Reineke Bok-Bennema, Brigitte Kampers-Manhe, and Bart Hollebrandse, 195-214. John Benjamins. URL https://doi .org/10. 1075/rllt.2.11lam. 
Lampitelli, Nicola. 2014. The Romance plural isogloss and linguistic change: A comparative study of Romance nouns. Lingua 140:158-179. URL https://doi .org/ 10.1016/j. . Iingua. 2013.12.011.

Landau, Idan. 2016. DP-internal semantic agreement: A configurational analysis. Natural Language \& Linguistic Theory 34:975-1020. URL https://doi.org/10. 1007/s11049-015-9319-3.

Matushansky, Ora. 2013. Gender confusion. In Diagnosing syntax, ed. Lisa Lai-Shen Cheng and Norbert Corver. Oxford: Oxford University Press. URL https://doi . org/10.1093/acprof : oso/9780199602490.001.0001.

Noyer, Rolf. 1998. Impoverishment theory and morphosyntactic markedness. In Morphology and its relation to morphology and syntax, ed. Steven G. Lapointe, Diane K. Brentari, and Patrick M. Farrell, 264-286. Stanford, CA: CSLI.

Oltra-Massuet, Isabel. 1999. On the notion of theme vowel: A new approach to Catalan verbal morphology. Doctoral Dissertation, Massachusetts Institute of Technology.

Oltra-Massuet, Isabel, and Karlos Arregi. 2005. Stress-by-structure in Spanish. Linguistic Inquiry 36:43-84. URL https ://doi .org/10 .1162/0024389052993637.

Passino, Diana. 2009. An element-based analysis of Italian nominal inflection. In Selected proceedings of the 6th Décembrettes, ed. Fabio Montermini, Gilles Boyé, and Jesse Tseng. Somerville, MA: Cascadilla Proceedings Project.

Percus, Orin. 2006. Antipresuppositions. Technical report, Japan Society for the Promotion of Science. Report of the Grant-in-Aid for Scientific Research (B), Project No. 15320052.

Percus, Orin. 2011. Gender features and interpretation: a case study. Morphology 21:167-196. URL http://dx. doi .org/10.1007/s11525-010-9157-2.

Pesetsky, David. 2013. Russian case morphology and the syntactic categories. Cambridge, MA: MIT Press.

Preminger, Omer. 2014. Agreement and its failures. Cambridge, MA: MIT Press.

Puškar, Zorica. 2015. Interactions of gender and number agreement: Evidence from Bosnian/Croatian/Serbian. Ms., University of Leipzig.

Radimský, Jan. 2006. Les composés italiens actuels. Doctoral Dissertation, Université Charles.

Sauerland, Uli. 2003. A new semantics for number. In Proceedings of SALT 13, ed. Robert B. Young and Yuping Zhou, 258-275. Ithaca, NY: Cornell Linguistics Club.

Sauerland, Uli. 2008. On the semantic markedness of phi-features. In Phi theory: Phifeatures across modules and interfaces, ed. Daniel Harbour, David Adger, and Susana Béjar, 57-82. Oxford: Oxford University Press.

Sauerland, Uli, Jan Anderssen, and Kazuko Yatsushiro. 2005. The plural is semantically unmarked. In Linguistic evidence, ed. Stephan Kepser and Marga Reise, 409-430. Berlin: Mouton de Gruyter.

Scott, John. 2002. Stacked adjectival modification and the structure of noun phrases. In Functional structure in DP and IP, ed. Guglielmo Cinque, 91-122. Oxford: Oxford University Press.

Spathas, Giorgos, and Yasutada Sudo. 2020. Gender on animal nouns in Greek. Catalan Journal of Linguistics 19:25-48. URL https://doi.org/10.5565/rev/catjl. 297. 
Steriopolo, Olga, and Martina Wiltschko. 2010. Distributed GENDER hypothesis. In Formal studies in Slavic linguistics: Proceedings of the formal description of Slavic languages, ed. Gerhild Zybatow, Philip Dudchuk, Serge Minor, and Ekaterina Pshehotskaya, 155-162. New York: Peter Lang.

Sudo, Yasutada, and Giorgos Spathas. 2020. Natural gender and interpretation in Greek: Comments on Merchant (2014). Glossa 5(1):1-42. URL https://doi.org/10. 5334 /gjg1. 1173.

Thornton, Anna M. 2009. Constraining gender assignment rules. Language Sciences 31:14-32. URL https://doi.org/10.1016/j. langsci.2007.09.003.

Wechsler, Stephen, and Larisa Zlatić. 2003. The many faces of agreement. Stanford: CSLI Publications. 
Pietro Baggio

Queen Mary University of London

Mile End Road

London E1 4NS

UK

p.baggio@qmul.ac.uk

Yasutada Sudo

University College London

2 Wakefield St.

London WC1N 1PF

UK

y.sudo@ucl.ac.uk 